ENSAYO 



\section{UNA MIRADA AL ECUADOR DESDE 1975}

\section{FERNANDO VELASCO ABAD ${ }^{1}$}

\footnotetext{
1 "Una formación social capitalista dependiente. Documentos para la discusión". La Nota previa de la cual se ha recabado la siguiente información fue realizada por Santiago Ortiz Crespo y señala: "Este documento fue elaborado por Fernando Velasco Abad en 1975 para la conferencia de la Unión Revolucionaria de los Trabajadores (URT), organización política de la cual surgió el Movimiento Revolucionario de los Trabajadores (MRT) del que sería uno de sus dirigentes. Es un documento de debate y análisis teórico político, que hizo Velasco como intelectual y militante político, fruto por tanto del debate colectivo" (Ortiz, S, 2013. Revisión de archivos de FVA, Tomado de URT, 1975).
} 



\section{UNA MIRADA AL ECUADOR DESDE 1975}

Por Fernando Velasco Abad

Fernando Velasco Abad (1949-1978) fue un intelectual comprometido con el cambio social del país, militante, educador de obreros y campesinos, economista de la PUCE (1970), fundador del Movimiento Revolucionario de los Trabajadores (1976) y de FODERUMA (Fondo de Desarrollo del Sector Rural Marginal Rural, marzo, 1978). Sus tres libros: Ecuador, subdesarrollo y dependencia, Reforma Agraria y Movimiento Indígena de la Sierra, y La dependencia, el imperialismo y las empresas transnacionales, son claves para seguir entendiendo a nuestro país. Estos son-entre otros - los legados que dejó en sus 29 años de vida 


\section{PRESENTACIÓN}

Fernando Velasco fue una persona de su tiempo y que siempre se destacó y descolló en el ámbito social en que se desenvolvió. Su origen familiar manabita por el lado materno fue preponderante en su trayectoria intelectual: su madre, docente nacida y educada en Chone, fue muy atenta e inteligente en estimular sus capacidades cognitivas en sus primeros años de vida. A los 12 años, Fernando ya constituía el asistente académico de su madre y le ayudaba a corregir exámenes de estudiantes de secundaria probablemente mayores que él. Este fenómeno atrajo la atención del rector del Colegio Benalcázar y su interés por conocer al precoz muchacho y preguntarle acerca de ¿qué es el arte?, a lo que el niño respondió "es el tratado de la belleza". Igual despertó el disgusto de sus compañeros de colegio que tenían que compartir el juego de billar con un niño con pantalones cortos que tenía que subirse a un taburete para empuñar el taco y golpear a las bolas de la mesa. El ejemplo de su tío educador, Gonzalo Abad, por muchos años funcionario internacional de la UNESCO y ex ministro de Educación del Ecuador, lo llevó a realizar viajes a París a visitar a sus parientes Abad-Ortiz y empaparse del mundo francés.

Ingresó todavía adolescente a la Facultad de Economía de la Pontificia
Universidad Católica, formando parte de una notable promoción académica de futura trascendencia en la administración de la institucionalidad estatal. Sus años universitarios estuvieron marcados por la lucha estudiantil por la organización gremial en su universidad y la fuerte radicalización juvenil mundial, en el contexto de la Guerra Fría, el conflicto vietnamita y la Revolución Cubana, la radicalización de la clase media, el auge petrolero y la dictadura nacionalista y revolucionaria del General Guillermo Rodríguez Lara. En esos años no era improbable que Fernando condujera una camioneta que no disponía de frenos y para detenerla estaba obligado a chocarla contra la vereda. Amigo del Tesorero universitario, poeta y dramaturgo, aficionado a las tertulias estudiantiles de media mañana en el bar universitario y distraído del pago mensual de los profesores. De esos años es su afición obsesiva por escalar el volcán Pichincha. Velasco Abad, ya para esos años contrajo matrimonio y engendró a su hijo Juan Fernando.

En el tiempo intermedio de los años 60 a y los 70, se inició políticamente en las filas demócrata cristianas y movimientos cristianos de cambio para luego comenzar un fuerte proceso de radicalización política hacia el activismo 
político de izquierda y marxista, aunque mantuvo la influencia de la teoría de la dependencia. Comenzó su carrera docente dictando clases en la Facultad de Economía de la PUCE y en la escuela de Sociología de la Universidad Central del Ecuador. En la primera universidad fueron años de apertura universitaria profundizada con el filósofo cuencano Hernán Malo Gonzáles (S.J) e iniciada con el padre Alfonso Villalba (S.J). Sin embargo, a mediados años setenta se desvincularía de la docencia para emprender la ruta del activismo político de izquierda experimentando una radicalización hacia la corriente sindical obrera, organizando el Movimiento Revolucionario de los Trabajadores (MRT) y promoviendo un cisma organizacional en la Central de Obreros Católicos del Ecuador (CEDOC), de tendencia demócrata cristiana. Al mismo tiempo fue funcionario de la Junta Nacional de Planificación y organizador de la agencia de desarrollo rural FODERUMA. En este trajín de hiperactividad organizativa sindical ocurrió su fallecimiento, a los 29 años de edad, en una obscura noche de julio de 1978 cuando cruzaba la ruta Alóag - Santo Domingo de los Colorados (actual Santo Domingo de los Tsáchilas).

Su obra inicial se enmarcó en la teoría de la dependencia, con su tesis de economista, publicada posmorten, por la Editorial El Conejo (Ecuador: Subdesarro-
Ilo y dependencia, 1981). Posteriormente, la misma editorial realizaría la publicación de otro texto: Reforma Agraria y Movimiento Campesino Indígena de la Sierra, Hipótesis para una Investigación. Asimismo, una publicación importante que se realizó cuando iniciaba su proyección política fue su ensayo en el libro Ecuador: Pasado y Presente. Su criterio era considerado por los medios de comunicación y era parte de debates políticos televisados en donde se destacaba por su lucidez analítica.

En la presente publicación se presenta un texto inédito que recoge su programa político-revolucionario, planteado a la Unión Revolucionaria de los Trabajadores, de cuyo seno surge el Movimiento Revolucionario de los Trabajadores (MRT). En este Velasco Abad analiza otros programas políticos, como el del Partido Comunista (PCE), línea de Moscú, y la del Partido Comunista Marxista-Leninista (PCMLE), línea china, y formula una línea política acorde con una visión de transición al socialismo pero no de objetivos socialistas de coyuntura. En términos de la coyuntura política similar a la planteada por el PCE, la lucha debería ser inicialmente "democrático-burguesa" pero en una estrategia socialista. Aquí, se puede verificar cómo sus exposiciones revelaban una claridad de argumentación notable en su pensamiento político y su compromiso personal de activismo 
de movimiento y no de élite de cuadros que con el tiempo se tornó en irrempladirigentes sobre la masa revolucionaria. zable para ser recordado por las actuales De ahí que, su desaparición no fue re- generaciones como un "Sociólogo de la emplazada por otros dirigentes de esa Universidad Central". solidez de pensamiento y dejó un vacío

Wilson Miño Grijalva

Quito, junio 25 de 2019 


\section{UNA FORMACIÓN SOCIAL CAPITALISTA-DEPENDIENTE}

Sin entrar a discutir la situación previa, se puede afirmar que, a partir de la Revolución Liberal, la sociedad ecuatoriana es predominantemente capitalista. Sin embargo, esta es una afirmación incompleta ya que estamos frente a un desarrollo capitalista específicamente determinado por la situación de dependencia. Se entiende aquí dependencia como un hecho que afecta estructuralmente a la sociedad y no como un simple marco externo que obstaculiza el desarrollo de un capitalismo nacional.

El hecho colonial determinó desde el inicio el desarrollo de una economía abierta e integrada estructuralmente al sistema capitalista mundial $y$, por tanto, a la división internacional del trabajo. El primer efecto de este hecho ha sido el secular drenaje de plusvalía que a través de múltiples canales es succionada hasta el último rincón del país y conducida a los centros del imperialismo. El segundo efecto es la imposibilidad de industrialización en tanto rigen las condiciones de división internacional del trabajo establecidas a partir de la Revolución Industrial.

Este carácter predominantemente agrario-exportador de nuestro desarrollo capitalista, supone un bajo nivel de desarrollo de las fuerzas productivas $y$, además, implica un lento, aunque soste- nido proceso de descomposición de las formas precapitalistas aún existentes. En el sector agrario que produce para el mercado interno, localizado especialmente en la Sierra, han predominado relaciones precapitalistas de producción, aunque subordinadas a las relaciones capitalistas, hegemónicas en todo el país. Esta subordinación aparece especialmente a través de los siguientes mecanismos:

a. El desarrollo de redes capitalistas de circulación que extraen excedentes del sector más atrasado y lo concentran en las áreas en las que priman las relaciones capitalistas; $y$,

b. La descomposición de las relaciones precapitalistas, en la medida que el sector capitalista agroexportador ha ido requiriendo de nuevos contingentes de fuerza de trabajo. En esta perspectiva, el desigual ritmo de expansión del sector agroexportador y el relativamente bajo nivel de desarrollo de sus fuerzas productivas, explican la persistencia del llamado "feudalismo" serrano.

En su conjunto, el desarrollo capitalista dependiente se ha caracterizado por su incapacidad para absorber en un marco de relaciones capitalistas al conjunto de la población. De esta suerte, no 
solo que se han mantenido las zonas precapitalistas, sino que además aparecen y se desarrollan los denominados "sectores marginales urbanos", esto es, grupos de subempleados cuyo volumen e importancia es creciente. Hay que aclarar que, de ninguna manera esto se debe a la falta de desarrollo capitalista, sino que, como se verá, es precisamente una característica del desarrollo capitalista-dependiente, incluso en su fase industrial. Además, hay que precisar que esta gran masa poblacional, si bien no constituye en estricto sentido un ejército industrial de reserva, de hecho cumple sus funciones de depresor de los salarios que rigen en las unidades capitalistas.

A partir de la década del 60 se inicia el proceso de industrialización en el marco capitalista-dependiente. La industrialización es posible por los cambios en la división internacional del trabajo que siguen la llamada revolución científico-tecnológica. Esto no supone una superación del carácter dependiente de las sociedades, sino únicamente, una transformación de ciertos mecanismos. Subsisten, por tanto, la situación subordinada en la división internacional del trabajo y la transferencia de plusvalía del país a los centros del imperialismo. Por las condiciones históricas que la preceden, la industria en el país es: a. Controlada por el imperialismo en términos de capitales invertidos, de tecnología utilizada y de abastecimiento de capital constante: maquinaria, materias primas y bienes intermedios.

b. Centrada en la producción de bienes de consumo para sectores de ingresos medios y altos que, como es evidente, son numéricamente reducidos.

c. Económicamente ineficiente, con altos costos de producción, requiriendo por tanto de protección estatal para competir con los productores similares importados; $y$,

d. Débil demandante de fuerza de trabajo.

El crecimiento del sector industrial y el dinamismo adicional que trae la explotación petrolera, significan un desarrollo de las fuerzas productivas y por tanto, un aceleramiento del desarrollo capitalista-dependiente que repercutirá en los sectores precapitalistas subordinados.

Concretamente, el sector rural que produce para el mercado interno se está transformando aceleradamente. Hay indicios de que a corto plazo van a aparecer unidades productivas típicamente capitalistas. Sin embargo, también parece que subsistirán en el campo 
sectores que concentren vastos grupos poblacionales, en los que rijan relaciones de tipo mercantil simple, y cuya función esencial seguirá siendo la absorción del excedente de mano de obra, al igual que los "sectores marginales urbanos", cuya magnitud, lejos de decrecer, aumenta con la industrialización dependiente.

\section{LA ESTRUCTURA DE CLASE}

El carácter de la formación social establece los condicionamientos objetivos para la estructura de clases y para el conjunto de prácticas de clase que van caracterizando las diversas coyunturas. Tradicionalmente —esto es, hasta 1960_, el bloque de clases dominantes ha estado homogenizado por la burguesía agroexportadora, la oligarquía tradicional. Con este término identificamos a los grandes comerciantes, importadores y exportadores, a los dueños de las grandes plantaciones y a los banqueros ligados al círculo comercial. Esta burguesía agroexportadora, como resulta evidente, cumplió la función de eslabón principal en la dominación imperialista.

Participando, aunque subordinadamente, en el "bloque en el poder" y manteniendo contradicciones con la burguesía agroexportadora - contradicciones que se agudizan en las fases de crisis de las exportaciones - tenemos a los terratenientes tradicionales, concentrados fundamentalmente en la Sierra. El carácter de las relaciones de producción en las cuales ellos son el polo do- minante, refuerza los rezagos feudales presentes en su ideología. Sin embargo, su carácter de grupo subordinado —en última instancia a la burguesía-, la descomposición paulatina de las relaciones precapitalistas de producción y su ligazón directa a los circuitos capitalistas de circulación, intercambio y acumulación, van rompiendo sus tradicionales mecanismos de articulación ideológico-político y van determinando su articulación en torno a su posición económica, expresándose a través de las cámaras de agricultura.

Hasta 1960 los industriales fueron básicamente apéndices de la oligarquía tradicional en la Costa y de los terratenientes de la Sierra. El crecimiento industrial va constituyéndose en fracción de clase independiente, que entra a disputarle la hegemonía a la burguesía exportadora y que, en muchos aspectos lo logra en la actual coyuntura, especialmente favorecidos por la crisis de las exportaciones tradicionales.

El carácter de la industria hace que objetivamente los industriales re- 
presenten la tendencia "modernizadora" del imperialismo. No existe, en ese sentido, una burguesía nacional y empresarial enfrentada al feudalismo y al imperialismo. No se descartan contradicciones secundarias de la burguesía industrial con la oligarquía y con las empresas imperialistas tradicionales, ligadas a la explotación y/o comercialización de productos del sector primario. Sin embargo, estas son contradicciones secundarias, propias del desarrollo capitalista dependiente, cuya fuerza depende de un conjunto de factores político-ideológicos y que por sí solas — correctamente aprovechadaspueden abrir etapas de acumulación de fuerzas populares en una perspectiva revolucionaria, pero nunca podrán abrir etapas revolucionarias.

Por el contrario, los estrechos lazos que han ligado la oligarquía tradicional con la burguesía, la flexibilidad de ciertos sectores oligárquicos que se aprestan a emprender una modernización controlada y la presencia hegemónica del imperialismo — que organiza el proceso de suerte de hacer prevalecer los intereses de su capital industrial transnacional, pero precautelando al mismo tiempo sus viejos intereses en los sectores agrarios y mineros - hace previsible la constitución de algo que hoy ya se entrevé: una burguesía centrada en la industria y en las finanzas y enraizada estructuralmente —esto es, a nivel de la producción - con el capital imperialista. Esta burguesía monopólica-dependiente que se está constituyendo es, entonces, el enemigo principal de las clases trabajadoras del Ecuador.

El campesino constituye, numéricamente, la mayor fuerza social entre las clases dominadas. Sin embargo, el carácter de su aporte a un proceso revolucionario apenas ha sido discutido. Tradicionalmente, y con excepción de los núcleos de jornaleros que trabajan en las plantaciones, el campesinado ha estado sujeto a un conjunto de relaciones de carácter precapitalista. En estas condiciones, su enemigo principal lo constituían los terratenientes y sus intereses de clase eran antifeudales y antiimperialistas, en la medida que el imperialismo tenía como interés básico un férreo mantenimiento del statu quo; sin embargo, esta situación está cambiando rápidamente. Como ya señalábamos, el desarrollo capitalista está descomponiendo las relaciones precapitalistas en el campo y estableciendo nuevas estratificaciones al interior del campesinado.

Tenemos, en primer lugar, al grupo de campesinos minifundistas y pequeño-propietarios; esto es, disponen de lotes de terreno iguales o usualmente menores de lo que constituiría una unidad agrícola familiar. La situación de este grupo es ambigua, ya que simultáneamente son productores para el mercado, 
propietarios de un lote de terreno que lo cultivan con la ayuda de la familia y, al mismo tiempo, en la mayor parte de los casos, vendedores eventuales de su fuerza de trabajo, ya sea en las haciendas cercanas, ya en las mayores ciudades, ya en las lejanas plantaciones de la Costa, a las que migran temporalmente. Desde el punto de vista de la infraestructura, estamos en presencia de un modo de producción mercantil simple con bajo desarrollo de las fuerzas productivas, lo cual permite que este sector siga manteniendo su carácter de zona de reserva que absorbe el excedente de fuerza de trabajo que no puede incorporar el desarrollo capitalista-dependiente.

Políticamente, la situación de estos sectores es ambigua. Sobre su nivel de conciencia pesan la lucha por la tierra y contra las injusticias feudales - que han tenido que emprender en la mayor parte de los casos - así como su diaria pobreza, la carencia de capital y de crédito, la falta de tecnología, y la presencia de un sistema de comercialización en el que habitualmente el campesino lleva la peor parte. Sin embargo, también actúan como frenos la conciencia individualista que emana de su propia práctica productiva, el carácter eventual de su relación capitalista y, lo que es fundamental, la ausencia física de un enemigo de clase, en cuyo enfrentamiento puede ir desarrollando crecientes niveles de politización.

\section{Es preciso especificar el carácter} de los grupos campesinos indígenas. En términos generales, su situación de clase es similar a la de aquellos grupos minifundistas y pequeños propietarios. Sin embargo, los especifica la discriminación de la cual son objeto. La discriminación racial es, en última instancia, un rezago ideológico feudal que perdura como mecanismo de reforzamiento de la explotación de los terratenientes y para permitir, además, la presencia de un grupo parásito de intermediadores - comerciantes, chicheros, tenderos, etc.especie de lumpen-pequeña burguesía rural. Esa dominación racial hace que este grupo tenga a corto plazo un mayor potencial de movilización. Sin embargo, quedarse en lo puramente racial rompe con cualquier perspectiva de clase, y por tanto, acaba por inmovilizar finalmente al grupo.

Tenemos, por otra parte, a los jornaleros —el clásico proletariado agrícola- que vende su fuerza de trabajo a unidades productivas típicamente capitalistas. Si bien, objetivamente constituye la principal fuerza de trasformación en el campo, en el momento actual, pese al desarrollo capitalista que se opera en el campo, su fuerza se ve limitada por la acción de la masa de campesinos semiproletarios que actúa como ejército agrícola de reserva y, además, por la crisis de la agroexportación que afecta a las plan- 
taciones que comienzan a demandar menos fuerza de trabajo. De esta suerte, buena parte de los jornaleros no logran insertarse como proletarios estables en una plantación, sino que deambulan por zonas relativamente amplias, trabajando eventualmente por temporadas no muy largas, lo cual limita tremendamente la probabilidad de organización y de reivindicación social.

Sus condiciones objetivas de existencia hacen del proletariado urbano, la fuerza dirigente del proceso revolucionario. Este papel protagónico ha sido oscurecido en función del relativamente escaso desarrollo industrial que lo limitó tanto cuantitativa como cualitativamente. El crecimiento industrial hace que crezca el proletariado y las grandes concentraciones fabriles. Crea, en definitiva, condiciones objetivas para el surgimiento de una poderosa fuerza revolucionaria. Sin embargo, también operan mecanismos desmovilizadores que refuerzan la acción global del sistema. En primer lugar, tenemos que en la situación de los obreros urbanos — por lo antes señalado — tiene un gran efecto la ideología del consumo, propia de una sociedad que se industrializa y que, por cierto, tiene un alto efecto desmovilizador.

Tenemos, en tercer lugar, entre las clases explotadas, aquella masa poblacional conocida como el "estrato marginal urbano". Sobre este sector se tienen más suposiciones que conocimientos concretos. Sin embargo, podemos señalar algunos aspectos relevantes:

a. Constituye, por su precarias condiciones de vida, un sector de alta explosividad potencial.

b. La carencia de un explotador directo que le haga visualizar la contradicción de una clase limita sus posibilidades de conciencia y de acción revolucionaria.

c. Ha constituido, por lo anterior, la base "natural" del populismo; y,

d. No es un grupo homogéneo, existiendo a su interior una profunda estratificación de artesanos, jornaleros eventuales, empleados de servicios y un proletariado que trabaja en sectores de muy baja tecnología, especialmente la construcción.

El gran desafío que presenta este amplio y creciente sector es su organización y movilización políticas en torno de sus intereses estratégicos y bajo la conducción política del proletariado.

Entre los propietarios y controladores del capital y las clases trabajadoras, encontramos un conjunto de grupos que cumplen funciones de intermediación técnica y social en el proceso de explotación y de control de las clases trabajadoras. Objetivamente aliados a los explotadores, su situación, sin 
embargo, crea condiciones para que al interior de estos grupos se dé con más fuerza la lucha ideológica. Además, su relativa vulnerabilidad económica abre posibilidades de una cierta radicalización política $y$, por consiguiente, de alianzas con el proletariado en fases de crisis. Sin embargo, también la posibilita una persistente ambigüedad ideológica que puede abrir, en etapas de crisis económicas y ascenso de la lucha de clases, campo para una salida autoritaria, represiva y hasta fascista.

El análisis de estos "grupos medios" o "clase media" — también empaquetados bajo el rótulo pseudocientífico de "pequeña burguesía" - es de fundamental importancia por su tamaño; no olvidemos que en el país la población universitaria es mayor que la del proletariado fabril; además, es absurdo seguirle dando el único tratamiento a una masa profundamente heterogénea. Se podría distinguir, entonces, a aquellos "sectores medios" que son propietarios de medios de producción; esto es un mediano empresariado, tanto industrial como comercial. En principio, estos sectores en la medida en que contratan fuerza de trabajo y extraen plusvalía, forman parte de la clase dominante. Sin embargo, es claro que su debilidad relativa - por la cual hablamos de burguesía media- abre paso a la existencia de contradicciones con la fracción hegemónica de la clase dominante: la burguesía monopólica dependiente.

¿Cuál es el carácter de esas contradicciones y hasta qué punto esta burguesía media puede ser movilizable en un amplio bloque antimonopólico y antiimperialista? Habría que hacer varias precisiones. En primer lugar, en términos económicos, es necesario distinguir entre aquellas empresas medias cuya subordinación al gran capital se va paulatinamente arruinando, y aquellas que aunque subordinadas, su nivel tecnológico y su especialización productiva les permite participar de las ganancias monopólicas que obtiene el gran capital. En segundo lugar, dado que la industria predominante se orienta hacia los sectores de medianos y altos ingresos, queda un mercado marginal, el sector de los bajos ingresos cuya demanda de ciertos rubros (vestido, alimentación), abre posibilidades de existencia a una industria "marginal" que opera con una tecnología no muy avanzada, con materia prima de baja calidad y con base en una superexplotación de la fuerza de trabajo.

Hay que tener siempre presente que la existencia de contradicciones a nivel económico, no determina mecánicamente los lineamientos a nivel político. En otras palabras, la burguesía monopólica dependiente y el imperialismo siempre tendrán todas las ganas en sus intentos de aglutinar en su conjunto a 
todas las fracciones de la mediana burguesía, en la medida que controla políticamente, en forma decisiva, los aparatos ideológicos del Estado.

Finalmente, el conjunto de empleados públicos, sobre los cuales opera una cierta criticidad respecto de la clase dominante, cuyos intereses políticos desquician los planteamientos y proyectos "técnicos", lo cual genera una cierta frustración.

\section{EL CARÁCTER DE LA REVOLUCIÓN}

Señalar el carácter predominantemente capitalista de la sociedad ecuatoriana, no significa necesariamente que la revolución deba ser socialista. El socialismo es una etapa en el desarrollo histórico de las sociedades. Su advenimiento no puede ser el resultado de la pura voluntad de los hombres, sino que solo es posible a partir de la existencia de determinadas condiciones objetivas centradas en un cierto desarrollo de las fuerzas productivas.

En esta perspectiva cobra sentido pleno la idea de que las distintas relaciones de producción que confieren su carácter a las sociedades concretas, tienen etapas en las que son formas de desarrollo de las fuerzas productivas. En otras palabras, la sucesión de diversas formas sociales no es un hecho casual, sino que responde a la necesidad objetiva —en condiciones concretas que especifican esas formas sociales - de impulsar el proceso de separación-transformación del hombre sobre la naturaleza. El ca- pitalismo tiene, por tanto, un lapso de vida "socialmente útil", en el que efectivamente impulsa el desarrollo de las fuerzas productivas. Superado ese nivel, no es que se estanca el desarrollo de las fuerzas productivas, sino que el sistema entra estructuralmente en una etapa de decadencia, ya que ha creado las condiciones materiales que permiten su superación. Es entonces cuando esas relaciones de producción, "hasta ayer formadas de desarrollo de las fuerzas productivas [...] se transforma en pesadas trabas. Se inicia entonces una era de revolución social” (Marx, "Prólogo a la Contribución a la crítica de la economía política").

Sobre estas bases, cabe preguntarse: ¿están maduras en el Ecuador las condiciones materiales para instaurar una sociedad socialista? O, dicho de manera equivalente: ¿es posible una revolución socialista en los actuales momentos? La respuesta es, evidentemente, no. El nivel de desarrollo de las fuerzas productivas es aún insuficiente como para establecer 
una sociedad socialista. Por ello, incluso haciendo abstracción de la correlación de fuerzas de las clases antagónicas, es un puro voluntarismo enarbolar hoy la bandera de la revolución socialista. Sin embargo, esto tampoco significa que la revolución tiene un carácter antifeudal, ni tampoco, que lo que debemos hacer es esperar pacientemente hasta el momento en que la propia evolución del sistema cree esas condiciones que posibiliten el tránsito al socialismo. Examinemos estas dos cuestiones.

Las denominadas "revolución democrático-burguesa" o "revolución nacional liberadora" parten del equívoco de considerar que el enemigo principal lo constituyen los sectores "feudales" y de que el imperialismo actúa exclusivamente a través de la burguesía comercial y, más modernamente, a través, además, de las empresas petroleras y de sus intermediarios. Esta tesis, planteada coincidencialmente, aunque con desigual grado de consecuencia por los partidos comunistas (prochino y prosoviético), se basa en un conjunto de errores y ambigüedades:

a. Desconocer que el modo de producción capitalista es el hegemónico en la sociedad ecuatoriana, planteando tesis confusas como: "el régimen económico-social del Ecuador en su conjunto no es pues ni feudal ni capitalista ("Línea general de la revolución ecuatoriana", en documentos del PCMLE, p. 8).

b. Plantear que existen obstáculos externos para el desarrollo capitalista del Ecuador y que estos obstáculos son las supervivencias feudales y el imperialismo. Así, en el programa del PCE se dice: "Los factores fundamentales que dentro de nuestra estructura económica y social detienen el progreso del país y hunden en la miseria al pueblo son la opresión colonizadora del imperialismo, en especial del imperialismo norteamericano y el mantenimiento de fuertes supervivencias feudales en el país" (p.3). Pero, hay que insistir que esta percepción del feudalismo y del imperialismo es totalmente antidialéctica, concibiéndose la acción del imperialismo - que controla nuestros recursos naturales, al igual que los rezagos feudales - como obstáculos externos no intrínsecos al desarrollo de un capitalismo nacional, totalmente abstracto y ahistórico, que solo existe en la imaginación. Más aún, la presencia de estos obstáculos es poco menos que metafísica, pues el imperialismo — según ellos - impone su dominación y los rezagos feudales existentes son puras razones políticas, errores y traiciones, y no por la propia configuración histórica de la 
estructura productiva ecuatoriana. Así, por ejemplo, la "Línea general de la revolución ecuatoriana" del PCMLE, dice que:

La Revolución Liberal de 1985 se detuvo ante la embestida contrarrevolucionaria de los terratenientes conservadores y la traición del ala derecha del Partido Liberal. [...] Quedó así intocada la estructura feudal del país. Desde entonces, la burguesía nacional ecuatoriana ha demostrado ser una fuerza capaz de destruir los rezagos feudales y de resistir, y menos abolir, la dominación imperialista (p.32).

c. Plantear, en la estructura de clases, a los terratenientes "feudales" como fracción hegemónica en estrecho asocio con el imperialismo el cual tendría intereses similares; $y$,

d. Desconocer la tendencia modernizadora que impulsa precisamente el imperialismo en concordancia con la nueva división internacional del trabajo que se va gestando desde finales de la década del 50.

Tampoco la respuesta es la de esperar pacientemente hasta el momento en que el desarrollo capitalista del país cree las precondiciones materiales para el tránsito al socialismo. Y esto no únicamente por el imperativo de acción que suponen las persistencias de nefastas e inhumanas condiciones de vida para las grandes mayorías nacionales, sino, además, porque el desarrollo capitalista-dependiente supone un desarrollo no solo desigual, sino desquiciado, de las fuerzas productivas, por la acción de un conjunto de elementos consustanciales a la estructura económico-social que detienen y deforman la evolución de las fuerzas productivas. Esto equivale a afirmar que el desarrollo capitalista-dependiente se torna históricamente freno para el desarrollo social, mucho antes de que las fuerzas productivas alcancen un nivel tal que permita el paso al socialismo. No son, entonces, rezagos feudales que borrar ni tampoco un cerco externo que se debe superar. El problema es más de fondo y atañe a una estructura que debe ser globalmente superada pero que, paradójicamente, aún no crea — ni tampoco puede crear - las condiciones materiales que permitan el establecimiento de un sistema social más avanzado.

Todo esto nos lleva a postular la necesidad de una fase de transición al socialismo y, por tanto, la existencia de una etapa revolucionaria en la cual económicamente se impulsa el desarrollo de las fuerzas productivas y en el cual el proletariado acumula fuerzas para asu- 
mir la hegemonía del proceso y transformar la revolución en socialista. Esta fase busca exactamente desbrozar los obstáculos que impiden un "capitalismo nacional". No es, entonces, una revolución antifeudal y antiimperialista, asumiendo como imperialismo solo los sectores tradicionales de inversión del capital extranjero. Es una revolución que trata de articular los intereses de las clases no hegemónicas de la sociedad para golpear a la fracción hegemónica, la burguesía monopólica dependiente $y$, por tanto, para golpear estructuralmente a la sociedad capitalista-dependiente. Es pues una revolución popular, democrática y nacionalista, que instaura una fase de destrucción del capitalismo-dependiente, de desarrollo para la construcción del socialismo. Consecuentemente, el programa revolucionario supondría los siguientes puntos básicos:

\section{a. Reforma agraria.}

b. Pleno control nacional sobre todos nuestros recursos naturales.

c. Nacionalización del comercio exterior.

d. Reorientación del proceso de industrialización, controlando la penetración del capital y de la tecnología extranjeras, creando un sector nacional de industria pesada con decisiva par- ticipación estatal, y el establecimiento de líneas prioritarias de asignación de recursos para los sectores prioritarios de la industria.

e. Redistribución del ingreso y elevamiento del nivel real de vida del pueblo.

f. Movilización y participación popular en las tareas gubernamentales y establecimiento de formas de control de los trabajadores sobre la producción como base de una nueva democracia.

g. Eliminación de todas aquellas agencias de penetración ideológica, control y espionaje que el imperialismo ha plantado en el país.

Estos puntos definen el carácter popular, democrático y nacionalista de la revolución, y además especifican el bloque básico de clases y grupos que pueden luchar por ella: las clases trabajadoras, los empleados, los grupos de intelectuales, clero, militares progresistas, e incluso los empresarios medios que tienen un carácter nacionalista. Es precisamente un desafío para la conducción política revolucionaria, entonces, constituir este amplio bloque, conseguir aislar al enemigo estratégico principal y luego establecer la hegemonía del proletariado al interior del bloque revolucionario. 


\section{LA COYUNTURA ACTUAL}

La coyuntura actual tiene que ser definida como una fase de transición entre dos etapas del desarrollo capitalista-dependiente del país. Hemos señalado ya el carácter de esa transición y el hecho de que el surgimiento de la industria significa un aceleramiento en el desarrollo de las fuerzas productivas. Cabe aquí precisar las implicaciones sociales y políticas de tal hecho.

Estamos viviendo una etapa de cambio en la estructura y prácticas de las clases sociales. Se están eliminando, por una parte, las relaciones semifeudales que pesaban sobre amplios sectores campesinos $y$, al mismo tiempo, crece y se desarrolla el proletariado industrial. En esta medida, crecen y se desarrollan las organizaciones de los trabajadores, ganando fuerza las posiciones clasistas y generándose un amplio proceso unitario desde la base. Por otra parte, se consolida como fracción independiente de clase la burguesía industrial, fuertemente ligada al imperialismo, que hoy opera a través de las empresas trasnacionales. Ello va acompañado del fortalecimiento de circuitos financieros especialmente ligados a este desarrollo industrial y, por cierto, al imperialismo.

A esta transición económica, de una etapa agroexportadora a una etapa industrial, le corresponde una transición de hegemonía al interior del bloque en el poder, pasándose de la hegemonía de la burguesía comercial a la de la burguesía industrial. Ello implica, por cierto, profundos cambios y rearticulaciones en las relaciones mantenidas al interior de las clases dominantes y, entre estas y sus clases y grupos de apoyo; implica además una gradual transformación de los mecanismos político-ideológicos de encuadramiento y de control sobre las clases dominadas, y por último, determina cambios en la estructura misma del Estado.

Esta modernización infra y supraestructural provoca, como es lógico, contradicciones entre los sectores viejos y nuevos de la clase dominante. Esas contradicciones son secundarias y, además, han sido amortiguadas, tanto por la capacidad de maniobra que supone para el Gobierno los ingresos petroleros, como por las relaciones preexistentes entre la oligarquía y los nuevos sectores industriales, lo cual se ha reflejado en la creciente importancia del sector derechista de la burguesía que busca llevar adelante el proceso de modernización con el menor costo social y político para la oligarquía.

El carácter transicional de la presente coyuntura impide plantear a cabalidad una línea política proletaria. Políticamente, hemos caracterizado la actual coyuntura como una fase en la cual la oli- 
garquía tradicional pierde fuerza, siendo reemplazada en la hegemonía social por la burguesía industrial dependiente que deviene en monopólica. Es precisamente en esta perspectiva que señalamos a esta burguesía monopólica dependiente como el principal enemigo estratégico de los trabajadores del Ecuador.

Una línea política solo puede surgir de la lucha política, esto es, de la lucha de clases. La utilización general de un método y de categorías científicas, nada más que eso. Solo cuando el análisis científico se liga a la práctica política es posible producir teoría revolucionaria, esto es, fundamentalmente, una estrategia y una táctica que no solo encarnen los intereses objetivos de las clases trabajadoras, sino que además partan de su situación concreta.

El desarrollo de las fuerzas productivas consolida el sistema y dialécticamente va creando las condiciones materiales y al sujeto histórico de su superación. La perspectiva revolucionaria lo que hace es acelerar la historia, nunca trata de detenerla. Aliarse, en la actual coyuntura, con los sectores más retrasados de la clase dominante para así tratar de detener la consolidación de la burguesía monopólica dependiente, es una pura ilusión, e ilusión peligrosa, pues las presuntas vanguardias que lo intentan acabarán o desligándose de las masas populares o conduciéndo- las a la total parálisis y desorientación políticas. En otras palabras, la actual debilidad política del proletariado y la carencia de condiciones materiales, le impiden prestarse, en esta fase de transición, como real alternativa inmediata. Por ello, el proletariado debe permitir el desarrollo del proceso histórico que dialécticamente creará esas condiciones objetivas, aunque el propio proceso consolide y fortalezca al enemigo principal en perspectiva estratégica.

Esta situación explica el por qué no ha surgido en el país una real alternativa revolucionaria frente a las posiciones tradicionales. El hecho de que pese a la larga y virulenta crítica realizada a la línea del PC (Partido Comunista) no haya surgido una estrategia política alternativa, revela la inexistencia de condiciones objetivas para el desarrollo de una línea que no sea una variante más del planteamiento antifeudal, antioligárquico y antiimperialista, entendido el imperialismo en su versión tradicional, limitado a la explotación de los recursos naturales. No es el caso tampoco de una línea que subsista por la absoluta corrección de sus supuestos, ya que buena parte de ellos han sido correctamente criticados. Se trata de una coincidencia histórica: las clases y fracciones planteadas como enemigos del proletariado, por el PC, no son en términos estratégicos, como lo plantean los comunistas, pero sí lo son en términos tácticos. 
Por ello, por su error estratégico, el planteamiento comunista no representa una línea auténticamente proletaria que exprese los intereses objetivos a largo plazo del proletariado, pero en cambio, es correcta en el corto plazo. Y por ello, en la medida en que no están plenamente constituidas las nuevas condiciones de la lucha de clases, cualquier intento de plantear una línea política proletaria no puede desembocar más que en una repetición con ciertas variantes de la vieja línea comunista como es el caso del más feroz impugnador del PC, el PCML (Partido Comunista Marxista Leninista)—, o bien se llegará al planteamiento — como pretende ser el presente documento- de ciertas tesis generales que aunque fueren correctas constituyen primeros elementos de discusión pero no una línea política en sentido estricto.

\section{LA LUCHA ANTIOLIGÁRQUICA Y LA ACUMULACIÓN DE FUERZAS}

Las condiciones históricas concretas determinan, en el corto plazo, la necesidad de seguir con una línea antioligárquica y antifeudal. La principal fundamentación de esta línea está, como lo hemos señalado, en el carácter progresista del movimiento de los trabajadores. Nuestra función es acelerar la historia y no detenerla: nuestra política es la de optar en base de realidades concretas y no de valores abstractos. Esta etapa es de acumulación de fuerzas; para ello, el movimiento de los trabajadores debe concentrar sus fuerzas en golpear políticamente a los sectores más atrasados y, relativamente más débiles, de la clase dominante.

Para lograr estos objetivos, es necesario borrar cualquier ilusión reformista que despierte la confusión entre los enemigos estratégicos y tácticos del movimiento de los trabajadores. El pueblo debe estar consciente de que golpeando a los terratenientes y a los comerciantes, no está haciendo la revolución aunque esté acumulando fuerzas para ello; debe estar consciente, por tanto, de que modernización no es revolución, e insistir en una auténtica independencia de clase, que sea producto de la clarificación sobre el real carácter de las fuerzas sociales en pugna.

Esta tarea de clarificación es, entonces decisiva, debido a las ambigüedades que la fase de transición trae para el proletariado. En este sentido, la tarea de una vanguardia no debe ser la de menospreciar al pueblo ocultándole la realidad o planteándole verdades a medias, 
con la esperanza de que las crean. Esta política, llevada sistemáticamente por el PCE —en parte por su anquilosamiento teórico, en parte por su sujeción a los intereses de la URSS - constituye un error que a la postre viene a desmovilizar y a desorientar a los trabajadores. Concretamente, es necesario discutir profundamente con los trabajadores, entre otros, sobre los siguientes puntos: (i) el carácter del Estado; (ii) el carácter no revolucionario, aunque progresista, de las consignas antifeudales y antiimperialistas, y (iii) El carácter para explotar nuestras riquezas, resaltando que sus capitales no solo penetran para explotar nuestras riquezas naturales, sino además para controlar la industria destinada al mercado interno.

Sin embargo de lo último, hay que recordar que poco pueden la reflexión y la discusión sin una práctica concordante. Para el proletariado ecuatoriano que está consolidado, su enemigo estratégico es la burguesía monopólica dependiente. Sin embargo, en esta fase se plantea como enemigo principal a la oligarquía, a los terratenientes y a los monopolios petroleros. En otras palabras, plantea una lucha política inmediata contra estos últimos, limitándose a un enfrentamiento económico-reivindicativo con la burguesía industrial dependiente, que va camino de convertirse en monopólica. Esta situación es ciertamente ambigua, ya que a mediano plazo, será contra esta última que el proletariado deberá descargar sus golpes políticos, por lo cual es imprescindible que la clase vaya asumiendo políticamente en su totalidad, el carácter de los procesos. Más precisamente, se plantea la necesidad de superar cualquier absurda separación entre una vanguardia - la cual se auto reserva el dominio de la política- y la clase organizada en sus aparatos de masas a los cuales les pretendería reducir al papel de correas de transmisión de las iniciativas políticas de la autoproclamada vanguardia y de simples mecanismos de lucha económica. 